\title{
Free will and the construction of options
}

\author{
Chandra Sripada ${ }^{1}$
}

Published online: 26 February 2016

(C) The Author(s) 2016. This article is published with open access at Springerlink.com

\begin{abstract}
What are the distinctive psychological features that explain why humans are free, but many other creatures, such as simple animals, are not? It is natural to think that the answer has something to do with unique human capacities for decision-making. Philosophical discussions of how decision-making works, however, are tellingly incomplete. In particular, these discussions invariably presuppose an agent who has a mentally represented set of options already fully in hand. The emphasis is largely on the selective processes that identify the options most worth doing and then execute them. But where do mentally represented sets of options come from in the first place? Once we focus on this constructive aspect of decisionmaking, an important fact becomes apparent: While the option sets of simpler animals are sharply limited, humans have a number of striking psychological powers - including remarkable powers of prospection and creativity - that enable them to construct option sets of unparalleled size and diversity. As a result, humans can express themselves in countless ways. This latitude for self-expression is, I argue, the distinctive feature that explains why humans are free.
\end{abstract}

Keywords Free will · Options - Could have done otherwise - Compatibilism · Phenomenology of freedom

Chandra Sripada

sripada@umich.edu

1 Department of Philosophy, University of Michigan, 2215 Angell Hall, 435 South State Street, Ann Arbor, MI 48109-1003, USA 


\section{Introduction}

Is free will possible at all, either in a deterministic world or an indeterministic one? This is what we might call the existence question of free will, and it has been the focus of most philosophical discussion. In this essay, I assume a non-skeptical answer to this question, i.e., I assume that free will exists and that unimpaired adult humans have it. I instead address an importantly distinct comparative question: What are the distinctive psychological features that explain why humans, but not other creatures, such as simple animals, are free?

One might think that any account that provides a satisfying answer to the first question will surely also address the second. But this is not so. My focus in this essay is on certain influential compatibilist theories of free will that do provide a plausible (albeit controversial) answer to the existence question but leave the comparative question largely unaddressed.

One of the compatibilist views I have in mind is that of classical compatibilists who say free will requires the ability to do otherwise. They typically analyze this ability in terms of satisfying certain counterfactual conditionals. Very roughly, were the agent's desires, choices, or assessments of reasons to be different than they actually are, she would do otherwise. Another kind of compatibilist view says freedom requires a certain sort of control. Standard analyses of control, however, turn out to be notably similar. An agent has the relevant form of control if the mechanism that issues in her action satisfies a requirement along the following lines: Across a suitable number of possible worlds in which there is sufficient reason to do otherwise, the mechanism recognizes the reason to do otherwise in that world and does otherwise. ${ }^{1}$

As I see it, one way to capture what these compatibilist accounts have in common is that they say that to be free, one's actions must stand in the right sort of dependence relation with respect to certain important agential features. The precise nature of the dependence relation differs across views, ${ }^{2}$ and the relevant agential features differ too (desires, decisions, the agent's reasons, etc.). While these differences are important, I want to put them aside. Going forward, I will refer to the common condition for freedom shared across these compatibilist accounts, i.e., the

\footnotetext{
1 This corresponds closely to the "responsivity" condition for control proposed by John Martin Fischer (Fischer 1987; Fischer and Ravizza 1998). Of note, he proposes control is needed for moral responsibility; he is agnostic as to whether it is required for free will (Fischer 2012b). Other philosophers, for example Daniel Dennett and Michael McKenna, understand control as a requirement of free will (see Dennett 1984; McKenna 2011).

2 The could have done otherwise view sets up a particularly strong dependence relation. Given a standard possible worlds semantics for counterfactuals, the could have done otherwise view says: In the possible world nearest to the actual world where the relevant agential features are different, the person does otherwise. The control-based view proposes a much weaker dependence relation. For example, Fischer's weak reasons-responsiveness condition says (roughly): There exists at least one possible world in which the relevant agential features are different, where this world need not be nearest to the actual world, and the agent (or more precisely, the mechanism that issues in her action) does otherwise (see Fischer and Ravizza 1998, p. 41).
} 
condition characterized in terms of this dependence relation, as a "control/could have done otherwise" condition. ${ }^{3}$

Importantly, these compatibilist theories that rely primarily on a control/could have done otherwise condition-while they do tell us something quite informative about the existence question-leave the comparative question largely unaddressed. ${ }^{4}$ We can see this point more clearly if we reflect on the psychological capacities that are involved in enabling agents to make decisions. It is useful to divide these into two types. The first type consists of constructive processes that enable an agent to build an option set. This is a mentally represented $\operatorname{set}^{5}$ of various candidate action plans and their anticipated outcomes. The second type consists of selective processes. Given an option set, these enable an agent to assign evaluative weights to the elements of this set. I leave it open exactly how these evaluative weights are assigned - this might involve integrating information about probabilities, utilities, the agent's desires, reasons, and perhaps other sorts of information or considerations as well. When the evaluative weights have been assigned, whichever action plan in the option set receives most weight is next selected for execution.

Notice that the compatibilist theories under consideration are primarily concerned with the selective component of decision-making. They are primarily interested in how we can make sense of the unconstrained operation these selective processes in a deterministic world. Their chief insight is that even if determinism is true, the dependence relation at the heart of control/could have done otherwise views can nonetheless be satisfied. This insight is naturally recast using the language of selective processes: When an agent possesses selective processes that are functioning properly-when these processes are "healthy" and unimpeded by environmental or psychic obstacles - then it follows that her actions will depend in the right sort of way on her assignment of evaluative weights, thus satisfying the control/could have done otherwise condition. On the other hand, consider compulsives or addicts battling irresistible urges. These agents' selective processes are compromised; they are insensitive to the evaluative weights that are assigned.

\footnotetext{
3 A number of others have noted the similarities between the standard analysis of control (such as the one due to Fischer) and analyses of the ability to do otherwise (see for example Watson 2001, p. 482; Ginet 2006, pp. 236-237). As Randolph Clarke observes, the similarities are still more striking when considering the more sophisticated analyses of the ability to do otherwise offered by the so-called "new dispositionalists" (see Clarke 2009, p. 341). See Franklin (2014) for a lucid discussion.

4 Two approaches to agency I have not discussed are Harry Frankfurt's hierarchical model (Frankfurt 1971) and Gary Watson's valuational model (Watson 1975). These are compatibilist theories that say that freedom depends on reasoning and reflective capacities that go well beyond a control/could have done otherwise condition. These theories are thus, at least prima facie, better positioned to address the comparative question. In my view, the main problem with these views is that they are not characterizing the commonsense notion of free will, but rather an importantly different notion, autonomous agency (for an extended and lucid discussion of this point, see Fischer 2012a). In any case, in what follows, I am really focusing on just those compatibilists, quite a large number, who offer theories that primarily involve a control/could have done otherwise condition.

5 Throughout this paper, "option set" is not used as a name for a set in the mathematical sense, i.e., a formal object that consists of a collection of elements. Rather, option sets are psychological entities. In particular, they consist of mentally represented bodies of information that play characteristic functional roles in an agent's mental economy.
} 
Thus, the dependence relation at the heart of the control/could have done otherwise condition fails to hold.

One serious problem for these compatibilist views, however, is that possessing selective processes, even fairly sophisticated ones, doesn't seem to be all that special or unique; such processes are in fact quite widespread in the animal world. Many creatures, such as birds, rabbits, and even honeybees, mentally represent candidate actions, e.g., continue to forage in this patch versus move on to the next patch. They assign evaluative weights to actions intelligently and accurately based on their current needs, expected costs and benefits, etc. Their actions in turn reliably depend on the evaluative weights so assigned; were these evaluative weights assigned differently, a different action would ensue. ${ }^{6}$ These creatures would thus seem to satisfy the dependence relation at the heart of control/could have done otherwise views, just as humans do. According to these compatibilist views, then, there is no reason to suppose a rabbit that moves its leg is any bit less free than a man who moves his hand. ${ }^{7}$ It is prima facie problematic for a theory of free will that it identifies the basis for freedom in a condition that holds just the same in man and rabbit.

It seems then that something important is missing in the compatibilist views under consideration. The control/could have done otherwise condition these views focus on helps to address the existence question of free will and is quite plausibly a necessary condition for freedom. But a control/could have done otherwise condition is satisfied by humans and simpler animals just the same. Thus these theories fail to adequately address the comparative question of free will. They fail to specify what are the psychological features distinctive to humans that explain why they are free while many other creatures are not.

In this essay, I try to fill in what is missing in these compatibilist theories. I argue that there is in fact a psychological feature that is distinctively possessed by humans and clearly freedom-relevant which is largely omitted from standard compatibilist accounts. This feature is what I call latitude. In contrast to the control/could have done otherwise condition that pertains to the selective aspect of decision-making, latitude pertains more directly to the constructive aspect of decision-making. Very roughly, latitude refers to what an agent gains when her constructive powers are more potent and the "size" of her option set grows larger. For now, we can say an agent has more latitude when the number of distinct options in her option set is larger. A bit later, I will provide a more refined account of option set size.

\footnotetext{
${ }^{6}$ The idea that animals mentally represent the expected value of options, and in particular separately represent the probabilities and utilities of these options, has been firmly established in experimental studies (Pyke 1984; Pyke et al. 1977; Schultz et al. 1997; Schultz 2010). For philosophically minded discussions see Railton (2014) and Seligman et al. (2013).

7 This example comparing the actions of a rabbit and a man is (intentionally) reminiscent of the discussion in the final section of Frankfurt (1971). Frankfurt first noted this general type of problem-that a theory provides a criterion for freedom that fails to distinguish creatures that are free from those that are not-for libertarian theories that understand freedom in terms of the categorical ability to do otherwise. But this form of criticism needn't be restricted to just this target, and can be leveled as well at a wide range of compatibilist theories.
} 
Simple animals have sharply limited latitude. The candidate options they can mentally represent and from which they can in turn select are few and relatively fixed. At the other extreme, humans have tremendous latitude. Humans possess a range of abilities for constructing options, and these abilities are distinctive in their scope and power. We have potent powers of prospection. We can generate hierarchically structured action plans that can grow to be large and complex. In addition, we have awesome powers of creativity - we can build options that differ substantially from what has come before. These constructive processes allow humans to build option sets that are strikingly large and diverse.

My defense of latitude as the answer to the comparative question of freedom is divided into three parts. In Part 2, I discuss the psychological capacities that confer on humans a vast amount of latitude. Part 3 clarifies the issue of how to understand the size of an option set. I argue that what matters for freedom is not the number of distinct action plans (i.e., the number of distinct ways of moving one's body) in the option set, but rather the distinct ways an agent can express her self in action. Part 4 argues that the latitude account gives us a new perspective on the phenomenology of freedom.

\section{The power to construct options}

Decision-making, I've suggested, involves two kinds of processes: construction and selection. ${ }^{8}$ In this section, I will be focusing on the differences in construction processes between humans and other animals. To get us started, consider two scenarios.

A rat approaches a fork in a maze and mentally represents two candidate actions available to it, going right or going left. Moreover, because it has explored the maze before, it has formed expectations of what would be the case were either option taken. The rat represents that going right will yield a reward while going left will not, and on this basis, the option of going right is selected.

Now contrast this scenario with a young woman in her second year of college. March is approaching and she is thinking about how to spend her Spring Break. Her friends will go to Tampa for a week of tawdry parties. Her family would love if she came home. She might stay in the dormitory and study, she thinks. If she is to get into medical school as she plans, she will need to do better in biochemistry, and the break will be a good chance to catch up in the course. She wants to go to medical school because physicians are respected and financially secure, but is this really her calling in life? She spends every free moment she can painting in the studio, and

\footnotetext{
${ }^{8}$ In distinguishing constructive and selective processes, I don't mean to imply a simple picture in which the two processes are strictly sequential, i.e., constructive processes unfold and only once fully complete, selective processes begin. Rather there is likely to be dynamic interplay between the processes. For example, one picture that seems plausible is that processes that construct options first build a skeletal sketch of the option. They then obtain a "preliminary read" from selective processes about whether the option is a serious competitor for choice. Only then do constructive processes elaborate the option more richly. This approach helps to save time and cognitive resources as "unpromising" options are discarded very early in the process. I don't raise these complexities in what follows because it does not bear on my main argument.
} 
that is the only thing she has ever really been passionate about. But is pursuing the arts even realistic? Better to deal with that question later, she thinks. For now, wouldn't it be wonderful to spend the entire break in the studio? She could work as much as she wanted with no schoolwork to interrupt her. Of course, the next tuition bill will be coming due soon. So she will need to do more work-study hours in the cafeteria. It would probably be best to do those hours during the break when there are fewer people around and fewer tables to clean. But what about being able to paint all break? And what about studying for biochemistry? And so it goes...

The example illustrates that the construction of options unfolds fast and furious, and with very little need for conscious guidance or supervision. She just sets her mind to think about what she could do and the options burst forth. The question I want to examine is, What explains the differential potency of human option construction? What enables humans to construct option sets that are much more massive in size ${ }^{9}$ than other creatures, such as the rat? In what follows, I will discuss five important psychological attributes that are key to the explanation.

I want to be clear at the outset that I am not arguing for absolute human uniqueness with respect to these five attributes. The picture I am putting forward is one of a complex continuum, with relatively clear cases at both ends and the absence of sharp demarcations in between. In certain animals (e.g., mollusks, crustaceans), the five attributes I will discuss are clearly lacking. In other animalsprimates, cetaceans, certain songbirds-it is likely that at least some of these attributes, or their precursors, are present, though much further research is required to clarify their level of elaboration. In humans, it is clear that all five attributes are present and manifest with high degrees of complexity and sophistication. It is this point-about the degree of elaboration in humans of these five attributes - that I mean to emphasize, rather than the claim that they are found exclusively in humans.

One factor that explains the differential potency of human option construction is that with humans, the individual options that are constructed are complex and consist of numerous constituent parts. Humans have the ability to form hierarchical plans, structured sequences of actions linked in a coordinated way to achieve a goal. Plans are characteristically decomposable into parts, each of which achieves some subgoal, and there is substantial flexibility in manipulating the parts through operations such as concatenation, reordering, and nesting. ${ }^{10}$

An emerging hypothesis ${ }^{11}$ proposes that a key substrate for hierarchical planning consists of combinatoric, hierarchical representational structures that are shared

\footnotetext{
9 For our purposes, it is good enough to think of the size of an option set in terms of the number of distinct candidate action plans it contains, irrespective of their content. I'll refine the notion of size in the next section.

${ }^{10}$ Karl Lashley conjectured that simple associative chaining accounts are inadequate, and the serial ordering of human action is best explained in terms of hierarchical plans (Lashley 1951). Miller et al. (1960) provides an early classic work on hierarchical plan structure. Rosenbaum et al. (2007) reviews evidence from multiple domains (chronometrics of action, errors in action performance, action sequence learning, and long-term skill acquisition) that supports the Lashleyian hierarchical view.

11 See Fitch and Martins (2014). Dehaene et al. (2015) proposes a related view in which there are potentially multiple mechanisms for representing sequences arrayed in terms of complexity. They too regard hierarchical structures, the most complex, as potentially being unique to humans.
} 
across the domains of language, music, and action. A major neural hub for these representations is Broca's area in inferior, lateral regions of prefrontal cortex, which in humans appears to be much more elaborated and interconnected with other brain regions than in primates and other animals.

Another closely related factor for explaining the differential potency of option construction in humans is extended time horizon. The existing evidence suggests that non-human animals cannot represent goings on at points in time in the distant future. Some studies place the time horizon of non-human animals at just a few minutes; others allow that in some contexts, the time horizon for some animals extends as far as a day. ${ }^{12}$ Humans, in contrast, can readily mentally represent events and episodes that are days, years, decades, and indeed millennia in the future, long after they as individuals, or even as a species, will have perished. The time horizon of humans may essentially be boundless.

The extended time horizon of humans is plausibly rooted in advanced abilities for episodic prospection. ${ }^{13}$ Humans have extensive episodic memory, memory for the who, what, where, and when information associated with an event. A leading hypothesis proposes that imaginative prospection into the future relies on constructive processes in which elements from episodic memory are recombined to generate the imagined future scene. ${ }^{14}$ While there is ongoing debate, many theorists believe that both of the preceding capacities, episodic memory and constructive recombination for creating prospective episodes, are either unique to humans or else dramatically expanded in humans relative to closely related primates. ${ }^{15}$

The preceding two factors-hierarchical planning and extended time horizonwork together to dramatically expand the space of potential options. Suppose a creature has 10 individual primitive actions it can perform, things such as running, pushing, grasping, chewing, turning, etc. If we allow the creature to assemble these primitive actions into integrated units for achieving subgoals, and allow the units to be assembled into complex hierarchical plans that unfold over fairly extended periods of time, then the creature will have available a massive set of options. For example, if we restrict a plan to consist of 20 such units, there will be many trillions of unique plans the creature can potentially undertake.

\footnotetext{
12 Time horizon in animals is an active and evolving area of investigation. In a detailed review of the literature, Roberts (2002) documents striking limitations in the time horizon of animals. For example, carefully controlled experiments in rats placed their time horizon at a maximum of roughly $30 \mathrm{~min}$, and in many contexts it appears to be much shorter. More recently, studies of food caching behaviors in western scrub jays have found that jays flexibly modify their patterns of caching and retrieving foods based on anticipated consequences that occur roughly a day later (Clayton et al. 2005; Raby et al. 2007). Other studies show primates save tools for use in the future. For example in one series of studies (Mulcahy and Call 2006), bonobos and orangutans preferentially accessed and stored tools useful for extracting grapes from an apparatus several hours to one day prior to gaining access to the site where the tools could be utilized (see also Osvath and Osvath 2008).

13 See Szpunar et al. (2014) and Seligman et al. (2013). For philosophical discussions of the role of episodic prospection (sometimes folded into the broader construct of mental time travel) in agency, see Gerrans and Kennett (2010) and Kennett and Matthews (2009).

14 See Schacter and Addis (2007) and Addis et al. (2008). De Brigard and Gessell (2016) offer an insightful related perspective.

15 See Suddendorf and Corballis (2007) and Suddendorf and Busby (2003) for useful reviews.
} 
Let me turn to another factor that contributes to the differential potency of human option construction: the ability for meta-representation, that is, the ability to mentally represent one's own psychological states. ${ }^{16}$ To see how meta-representation expands the size of option sets, consider an agent with various action-guiding psychological states, including various desires, cravings, cares, concerns, evaluative beliefs, habits, character traits, principles of choice, and so on. Let us suppose this agent lacks meta-representational capacities. Now consider a second agent who has precisely this same set of action-guiding psychological states, but who differs in having robust meta-representational capacities.

Notice that this second agent will have vastly more options that she can construct. For each psychological attitude that she has, i.e., for each desire, craving, care, concern, and so on, she can construct options in which she maintains, accentuates, resists, regulates, extinguishes, or in some other way modifies this attitude. Indeed, she can construct options in which she cultivates entirely new attitudes that differ from anything in her existing psychological repertoire. The first agent who lacks meta-representational abilities cannot recognize and mentally represent her own psychological states in this way. Thus she can't see her own mental states as "optional," as things that could be different were certain courses of action undertaken. Because of this deficit, her space of options is importantly constrained.

An additional factor that helps to explain the differential potency of human option construction is creativity. Consider some examples. It seems to everyone that it is impossible to breach the walls of Troy, but Odysseus devises a brilliant plan to accomplish this. Cyrano takes himself to be too hideous to share his feelings with Roxanne, but he hits upon an idea: he can express his feelings for her in letters that are disguised to be from someone else. Siddhartha sees suffering all around him. After extensive meditation, he emerges with an eightfold path aimed at its cessation. Seeing that everyone carries around a cell phone, Jobs invents a way to place the functionality of a personal computer inside of it.

Humans have remarkable abilities for creativity. According to current theories in cognitive science, a number of components are involved in underwriting creative thinking. One component is facility with divergent, "non-linear" thinking. ${ }^{17}$ This mode of thinking is tested in tasks that pose open-ended questions (e.g., How many uses can you come up with for a paper clip?), and the measure of success is the number of acceptable responses made in a fixed amount of time. Creativity also appears to be linked to analogical reasoning. ${ }^{18}$ Analogy has been proposed to involve forming an isomorphism between the objects and relations that hold across

\footnotetext{
16 According to an influential hypothesis attributed to ethologists Wolfgang Kohler, Norbert Bischof, and Doris Bischof-Kohler (Bischof 1980; Suddendorf and Corballis 2007), non-human animals are unable to represent future events in which they have motivational states that differ from their current motivations for the purposes of planning for their future needs. For example, a sated animal cannot represent the fact that it will be hungry in the near future and thus plan for this eventuality. This hypothesized constraint in animal cognition plausibly arises due the absence of a capacity for meta-representation, which would be required for an animal to represent its future desires.

17 See Runco (1991), Baer (1993), and Kim (2008).

18 See Holyoak and Thagard (1996), Gentner et al. (1997), and Johnson-Laird (1989).
} 
two distinct domains. ${ }^{19}$ Once an isomorphism is discovered, known operations applicable to one domain might lead to the development of novel corresponding operations in the second. Other theories emphasize the "perseverance" aspect of creative thought: Finding creative solutions requires brute force, iterative generation and testing of innumerable combinations of ideas until a suitable solution is found. ${ }^{20}$

The psychology and neuroscience of creativity remain active areas of investigation, and the preceding represent only a small sampling from this literature. The point I want to emphasize is that because of the kinds of processes discussed above (as well as other processes not discussed here or not yet discovered), we are an intensely creative species. When we face obstacles in our way, we invent new ways around them. As a result, the option sets we construct are always expanding.

The final factor I will consider that helps to explain the differential potency of human option construction is elaborate technological infrastructure. When I seek some amusement, I can watch movies on my iPad. If I need some consolation, I can talk on the phone with a dear friend in New Delhi. If I am hungry, just a key press is required for any of a hundred restaurants to deliver food to my door. Our environments are suffused with technologies that expand the range of things we are capable of doing. This is not true of just the contemporary era. Even in Neolithic times, humans possessed tools-fire, axes, shoes, pelts, seeds-that vastly expanded what they were capable of achieving.

We must be careful in how we understand the relationship between elaborate technological infrastructure and the size of one's option set; the former doesn't directly increase the latter. Rather, technology directly affects only the affordances present in the environment, the set of things that can be brought about by suitable sequences of actions. In the absence of suitable technology, a pile of wood is just that. But in a cultural milieu that possesses the appropriate technologies, a pile of wood can be the means to stay warm (by starting a fire), stay dry (by building a hut), or stay fed (by making a spear). Now, humans are exquisitely well equipped cognitively for detecting the affordances that are out there in the environment and translating them into mentally represented options in the head. Thus technology, by dramatically expanding the affordances present in our environments, plays an indirect role in expanding the mentally represented options that we can construct. ${ }^{21}$

The preceding five factors - hierarchical planning, extended time horizon, metarepresentational capacities, creativity, and elaborate technological infrastructurework together to help to explain the remarkable human ability to build option sets that are vast in size, and certainly bigger than any other creature in the animal world.

\footnotetext{
19 See Gentner and Markman (1997) and Gentner et al. (2001).

20 See Campbell (1960) and Simonton (1999).

21 The development of an elaborate technological infrastructure is intimately linked to culture, which allows technological know-how to be maintained, with accretion of incremental improvements, over extended stretches of time (see Boyd and Richerson 1988). It is likely that culture is itself made possible by certain cognitive capacities, in particular highly sophisticated abilities for social learning, that are distinctively human (see Tomasello 1999, 2009 for a discussion). Dennett has also noted links between culture and free will in his Freedom Evolves (Dennett 2004), though his discussion relies on a controversial "meme-based" view of cultural change.
} 
Moreover, this is no idle ability that we possess but rarely use. Constructing options is a ubiquitous activity. We spin out options at a rapid clip whenever the situation demands it, and also when it doesn' $\mathrm{—-when} \mathrm{we} \mathrm{are} \mathrm{sitting} \mathrm{quietly} \mathrm{just} \mathrm{daydreaming.}$ In the next section, I will ague that our potency in building options enables us to have a remarkable amount of latitude, and latitude is the distinctive mark of free will.

\section{Options for self-expression}

\subsection{The "size" of an option set}

Consider the following intuitive principle:

O: To be free is to have options and to have more options is to be more free.

In this section of the paper, I want to use $\mathbf{O}$ as a starting point to build a novel approach to free will. The account says that as the "size" of an option set grows, the person commensurately has more latitude and thus more freedom. In order to set out and defend a view along these lines, the first thing I need to do is say what makes an option set larger, i.e., what makes it the case that a person has "more options."

One approach that seems implausible is to equate the size of an option set with the number of distinct action plans within it. If this approach were correct, then a person's option set would be larger and her latitude - and thus her freedom-would be expanded when countless useless and absolutely irrelevant action plans were added to the set (e.g., wiggle one's little finger $1 \mathrm{~mm}$ once, wiggle one's little finger $1 \mathrm{~mm}$ twice, and so on).

There are two problems with the preceding account. First, what appears to matter for freedom is not the number of distinct action plans an option set contains, but rather the number of distinct ways of expressing one's self in action. Freedom is expanded only when the additional entries to one's option set represent meaningful expressions of one's values and cares, i.e., those psychological states that specify one's basic evaluative take on the world. The second problem is that we need to capture the idea of diversity of options. An option set has greater size when the options within it are, in a sense to be made precise, divergent: when they speak to very different aspects of one's self. To sum up, my proposal is that the size of an option set is based on the number and diversity of opportunities for self-expression that are contained within. Let me turn now to clarifying the key elements of this proposal.

What does it mean to express one's self in action? Elsewhere I offer a detailed theory that includes an account of the self and an account of the expression relation. ${ }^{22}$ Thus my remarks here will be brief. Luckily, little is sacrificed in aiming for succinctness, as the relevant ideas are quite intuitive.

People care about different things: health, wealth, prestige, relationships, justice, pleasures that range from the most refined to the most carnal, and so on. Caring goes beyond merely desiring something. When a person cares for something, she is

22 See Sripada (2015). 
committed to it in a fundamental, intrinsic, and diachronically cohesive way. A person expresses her self in action when her caring for something manifests itself in what she does. Recall the young woman who is passionate about painting. Suppose she gets up at 6 a.m. and trudges across town for an art exhibition. In acting to further something she cares about, with this very aim in mind, then her caring for that thing is expressed in what she does.

Selves are invariably complex, cacophonous things. People care about a multitude of different things, with their sundry cares sometimes in subtle, or not so subtle, tension with each other. ${ }^{23}$ To express one's self doesn't require one's action to speak for all of one's cares, or a sizable number of cares, or some overall weighted average of them. An expression of one's self needs to be anchored in just one care. Consider a scientist who cares about knowledge, power, fame, career, and status and thus spends all his time engaged in his work. But he also has a passion for ice climbing; he has since he was a boy. When he spends a month on an iceboat excursion in southern Chile, he does not advance, and indeed he sets back, many of the other career and status-related things he cares for deeply. Yet his taking this monthlong trip is very much an expression of his self.

Since people care about a multitude of things, and since expressions of the self need to be anchored in just a small part of the self, i.e., just a single care, then there are correspondingly a massive number of distinct expressions of the self that are possible. They correspond to all the different ways of expressing different subsets of one's self. According to my proposed account of the size of an option set, as a person engages in the sophisticated kinds of constructive activity described in the previous section and thereby constructs more and more options that are expressive of her self, the size of her option set correspondingly grows.

Increasing the number of self-expressive options is only one way for an option set to grow in size. To explain the other way, let me set out what it means for two options to be divergent. In Existentialism is a Humanism, Jean-Paul Sartre presents a story of a young man who faces the choice of going to England and fighting with the French Resistance or staying home and taking care of his frail mother. While Sartre had his own purposes for the story, what is most striking to me is the way the young man's options speak for two entirely distinct aspects of his self. Fighting for the Resistance resonates with the man's patriotism, his hatred of the enemy (his brother was killed by the Germans), his sense of adventure, and his pursuit of honor and glory. But the young man also deeply loves his mother, who doted on him as a boy and who wants him to stay home. Were the man to go to war, it would plunge her into despair. By staying home, he respects his mother's wishes, tends to her health, and ensures his own life and livelihood.

Think of one's options as lying in a multidimensional space. Each of one's cares establishes a new axis. The position of an option along that axis is determined by whether the option satisfies, hinders, or is neutral with respect to the satisfaction of that care. The notion of divergence can be understood as distance between two

\footnotetext{
${ }^{23}$ Elsewhere, I distinguish the mosaic conception of the self, which allows conflict within one's fundamental self, from the alternative homogenous conception of the self. I am presupposing the mosaic conception of the self in these remarks. See Sripada (2015).
} 
options in this high-dimensional space. The young man's options are highly divergent in that they lie at opposing "corners" of this space. A diverse option set is one in which the options within it are spread out and cover the space. That is, there is sufficient divergence between individual options that they are not all clustered within a tiny region.

I have proposed that the size of an option set is based on the number and diversity of opportunities for self-expression that are contained within. Now let me say what latitude is. Latitude is not the size of the option set itself. Rather, it is something an agent enjoys in virtue of her option set's size. Let us suppose a person's selective processes are functioning properly. Given an option set that has already been constructed, these processes appropriately assign evaluative weight to the options and select for implementation those that are evaluated as best. Because these selective processes are functioning well, the person meets the control/could have done otherwise condition that is at the heart of most compatibilist theories: her actions appropriately depend on her evaluations such that if the latter change, the former change as well. Holding fixed this fact, suppose now we enlarge the option set over which these selective processes operate, either by increasing the number of options or increasing the diversity of options. Even though the selective processes themselves have not changed-they still ensure the person has control over her action or that she could have done otherwise-the person's latitude has changed. Latitude consists in the opportunities for self-expression that have grown due to the expansion of the option set. ${ }^{24}$

Because of our uniquely powerful constructive powers, we humans build option sets of unrivaled size. We correspondingly have remarkable latitude of selfexpression. I contend that it is the latitude we enjoy when we act that is the distinctive mark of free will. That is, what best explains why we humans have far greater freedom than other creatures is that we possess far greater latitude for selfexpression.

\subsection{Selective processes revisited}

I have focused on powers to construct options as the distinctive basis for free will. Humans, however, also have uniquely powerful selective processes. That is, the processes that underlie our ability to assign evaluative weights to actions and implement those actions evaluated as best are also more advanced than those possessed by other creatures. One might object to the latitude view of free will for being too narrowly focused on the psychological processes that underlie option construction. Why not say that gains in sophistication of all the processes that subserve decision and action-the processes that subserve option construction as well as the processes that subserve option selection-contribute to freedom?

\footnotetext{
${ }^{24}$ It is worth emphasizing that on my account, latitude is a graded notion; the amount of latitude that an agent possesses scales with the size of her set of options. Notice that, holding fixed other factors, the degree of latitude possessed by an agent seems to quite naturally correspond with the degree to which that agent is free. This observation counts in favor of the latitude account.
} 
My response to this objection takes note of the fact that agency is a complex and multifaceted phenomenon. Because of this, we have a rich and nuanced vocabulary for separately describing distinct "achievements" of agency. For example, agents can be free, responsible, prudent, moral, virtuous, etc., and each of these terms picks out a distinct way that agency can go well. One important achievement of agency specifically concerns the functioning of selective processes. When these processes are made to function better, i.e., when evaluative weights are assigned to actions in a way that better reflects the "reason that there are" for performing them, we don't say the agent is thereby more free; rather we say the agent is thereby more rational.

To see more concretely how constructive and selective processes differentially contribute to freedom, consider a pair of hypothetical cases involving two creatures. Creature $A$ has limited constructive processes. In whatever situation it faces, it builds a meager option set consisting of just a few fairly simple, stereotyped candidate actions. But the creature has well-developed selective processes, and the evaluative weights it assigns to whatever actions are in its option set are highly accurate; they reliably represent the strengths of the "reasons that there are" (prudential, moral, etc.) for performing the relevant actions. Creature $B$ has dramatically more powerful constructive processes. It can mentally represent sophisticated multipart plans, has an extended time horizon, etc., and it routinely builds option sets that are vast in size and highly diverse in contents. Its selective processes are, however, relatively underdeveloped, and it makes errors in assigning evaluative weights. For example, it is too easily swayed by salient short-term gains or it often misjudges how its actions affect the interests of others. Thus, relative to creature $A$, its evaluative weights less reliably represent the "reasons that there are" for performing the relevant actions.

I believe it is clear that the advantage creature $A$ has over creature $B$ is not an advantage in freedom. Rather, it is an advantage in rationality. Creatures $A$ 's selective processes are better at selecting whichever option in its options set is in fact best despite the fact that its option set is highly constrained. The advantage creature $B$ has over creature $A$, in contrast, does seem to be an advantage in freedom. Creature $B$ can select from numerous and diverse options despite the fact that its selective processes are more prone to error and sometimes select a worse option. This pair of cases illustrates that when we pull apart the degree of sophistication of constructive processes and selective processes, freedom has a distinctive tie to the former and the latitude for self-expression that they enable. ${ }^{25}$

It bears emphasis that the latitude account developed here does allow that a certain degree of rationality is a necessary condition of freedom; freedom requires at least minimally functioning selective processes for assigning evaluative weights

\footnotetext{
25 "Reasons-responsiveness" approaches have loomed large in the recent free will literature (see Fischer and Ravizza 1998). It might be possible to, at first glance, think that latitude and reasons responsiveness are basically the same thing, i.e., that having more latitude amounts to being more responsive to reasons. The contrast between creature $A$ and creature $B$ should help to make it clear that this is incorrect. Creature $A$ has a high degree of reasons-responsiveness because across a wide range of possible scenarios where there is reason to do otherwise, it does so. It has only limited latitude, however, because its option set is always very small. For creature $B$, the reverse is true.
} 
to actions and selecting those deemed best. But it says that what distinguishes humans from other animals specifically in terms of freedom is not more refined selective processes. Rather, it is in virtue of our distinctively powerful constructive processes, which produce options sets that are far larger and more diverse than other creatures, that humans are distinctively more free. ${ }^{26}$

\subsection{Deep self approaches to moral responsibility}

There are important connections between the latitude account of free will and socalled deep self theories of moral responsibility. ${ }^{27}$ According to deep self views, a person is morally responsible for an action if and only if it is expressive of her self. A person who acts out of ignorance of what she is doing, or from an irresistible desire from which she is completely alienated, does not express her self in her action and thus she is not morally responsible for it. The latitude account of free will complements this picture and provides an attractive way of understanding the relationship between moral responsibility and freedom. In expressing our selves in action, we are morally responsible for what we do. Freedom adds something valuable to this: An agent is free to the extent that she can perform numerous and diverse self-expressive actions. ${ }^{28}$

\subsection{Limitations on latitude}

Control/could have done otherwise views give us a useful perspective on conditions that limit freedom. They highlight cases of force, compulsion, addiction, etc., cases that restrict an agent's control and ability to do anything else other than what she does. Since the latitude account accepts that free will requires satisfying a control/could have done otherwise condition, it too recognizes these as cases in which freedom is limited or erased. It goes further, however, as there are cases in which latitude, and consequently freedom, are limited that are not adequately captured by control/could have done otherwise accounts.

One pathway by which latitude might be limited involves constraints in constructive processes, which result in option sets that are relatively meager in size

\footnotetext{
${ }^{26}$ Many contemporary accounts of free will attempt to link it tightly with rationality. For example, Watson (1975) says free will consists in one's actions aligning with the verdicts of one's faculty of Reason, and Wolf (1993) says freedom consists in one's ability to act in accordance with the "reasons that there are." I would argue these authors are overemphasizing the role of rational powers and neglecting the latitude aspect of freedom.

27 Susan Wolf offered the original detailed formulation of a deep self theory of moral responsibility. I offer an alternative version in Sripada (2015).

28 Many philosophers understand free will in the following way: It is that capacity, the appropriate exercise of which, makes it possible for us to be morally responsible for our actions [see, for example, the introductions of O'Conner (2013), Pereboom (2001), and Clarke (2006)]. This is what one might call a "freedom first" perspective: free will is the more basic capacity and moral responsibility is something we enjoy when this capacity is exercised in the right way. I am here advocating a "responsibility first" perspective. Morally responsible agency is more basic. Freedom consists of morally responsible agency (i.e., self-expressive agency) plus something extra: latitude to express one's self in numerous and diverse ways.
} 
and lacking in diverse, self-expressive content. One way this can occur is through fairly stable psychological alterations. For example, individuals with certain kinds of autistic spectrum traits appear to have difficulties with prospective thought and imagination. ${ }^{29}$ This constrains, in a fairly fixed and enduring way, the number and range of the options they can construct.

Constructive processes can also be limited by more ordinary features of our psychologies. Some individuals simply don't want to put forth time and effort into mentally constructing options, they are not in the habit of doing so, or they lack the requisite skills and fall prey to characteristic biases and errors. ${ }^{30}$ Though they could exercise their constructive processes far more vigorously, because they don't care to do so or don't know how, they end up with impoverished sets of options. Limitations due to motivation and habit become more sinister when certain larger societal forces play a predominant role in shaping key psychological attitudes. For example, societal ideologies, in some cases oppressively imposed and in other cases non-coercively accepted, can shape beliefs, values, hopes, and habits so pervasively that the boundaries of what options one takes to be available are sharply constricted. ${ }^{31}$

There is another pathway by which latitude can be limited. Latitude depends on the number and diversity of self-expressive options. A person with a self that is unusually monolithic_-for example, a person who cares for just a single thingcannot construct highly divergent options that satisfy a variety of different cares. Her option set will thus be much smaller, she will not have very much latitude, and she will thus have highly limited freedom. This implication of the latitude account might initially seem counterintuitive, so we need to consider it in more detail.

To assess this implication, it is important to recognize that a person who fits this description would be radically outside the ordinary. If we fail to recognize this, we might imagine someone just merely uncommon, say someone like Mother Theresa. We might think surely she is single-minded in her caring for the poor, and then proceed to ask ourselves whether she is also constrained in her freedom.

After a moment's reflection, however, we should realize that though Mother Theresa certainly prioritizes helping the poor to an unusual degree, she clearly cares about a diversity of things in addition to the poor. For example, she doesn't kill the rich and take their money to help the poor, so she cares about other sorts of moral requirements. She also eats, bathes, prays, etc., and these things reflect her cares, and so on.

To get at the interesting implication at issue, we have to pick a far more extreme example. Suppose a yogi cares only about engaging in deep meditation. He truly doesn't care about anything else whatsoever. He cares not a whit about everything else including eating, sleeping, family, pleasure, even living. When he builds a

\footnotetext{
29 See Craig and Baron-Cohen (1999) and Lind and Bowler (2010).

30 Sternberg and Lubart (1991) offers an influential componential model that highlights the role of motivation, knowledge, and habits of personality in creative thinking. Mumford et al. (2006) and Amabile and Gryskiewicz (1989) discuss errors and biases that limit creativity.

31 See Huebner (forthcoming) for a discussion of how shared intentions and collective agency expand the set of possibilities we can jointly construct, though in certain cases they can also sharply limit it.
} 
mentally represented option set, the set contains only one self-expressive option: the option of meditating. Indeed his option set can only ever contain just this single selfexpressive element, since there is absolutely nothing else he cares about. I believe if we are careful to imagine such an agent whose option set is limited in this way, we would indeed say something is missing in terms of freedom.

\subsection{A focus on determinism}

As I noted at the start of this essay, many compatibilist theorists have long emphasized satisfying a control/could have done otherwise condition as the basis of freedom. Why has latitude long been ignored? Let me offer a brief explanation.

These compatibilists usually say they are providing an account of freedom, and this implies they are providing conditions that are individually necessary and jointly sufficient for freedom. But when we look more closely, they are often in fact doing something else. What they are actually doing is heavily shaped by the fact that discussions of free will usually take place in a conversational context in which skepticism about free will is highly salient, and this is in turn (usually) due to concerns about determinism. So it is perfectly natural for these compatibilists to emphasize how certain specific capacities of agents that seem necessary for freedom and that initially seem hard to reconcile with determinism—such as control or the ability to do otherwise - can in fact be so reconciled. As a result, these compatibilist accounts typically encompass a subset of freedom-relevant capacities, the ones that appear at least initially to clash with determinism. Any other capacities that are important for freedom and don't ostensibly clash with determinism don't typically make it into their accounts; they are largely overlooked. ${ }^{32}$ This, I believe, is what has happened to latitude. The operation of the constructive capacities that underlie latitude don't obviously clash with determinism. Their role in freedom thus hasn't registered very much with philosophers.

At the start of this essay, I divided questions about free will into an existence question and a comparative question. My hope is that in highlighting this distinction, we can better see what certain compatibilist views, in particular control/could have done otherwise views, get right: they provide a plausible answer to the existence question. We can also better see where they are incomplete: they leave the comparative question largely unaddressed. Because they don't engage the comparative question, these compatibilist views end up being much too inclusive; they imply that all creatures that satisfy the control/could have done otherwise condition, including rabbits and certain insects, are free. A theory that addresses both the existence question and the comparative question, on the other hand, provides a more complete account of freedom, an account that more closely captures_in an illuminating way-all and only those creatures that are free.

\footnotetext{
32 See Nahmias (forthcoming) for a similar view that compatibilists' focus on determinism has led them to overlook other psychological capacities relevant for free will.
} 


\section{The phenomenology of freedom}

A number of philosophers have offered reports of the subjective experience of free will. One theme that looms large in these descriptions, indeed nearly to exclusion of everything else, is the ability to do otherwise.

For example John Searle writes.

...reflect very carefully on the character of the experiences you have as you engage in normal, everyday human actions. You will sense the possibility of alternative courses of action built into these experiences... [T] he sense that 'I am making this happen' carries with it the sense that 'I could be doing something else'. In normal behavior, each thing we do carries with it the conviction, valid or invalid, that we could be doing something else right here and now, that is, all other conditions remaining the same. This, I submit, is the source of our own unshakable conviction of our own free will (Searle 1984, p. 95).

Searle's descriptions are highly controversial. Compatibilists offer their own reports of what it feels like to have the ability to do otherwise that differ from Searle's libertarian characterization. ${ }^{33}$

I won't try to adjudicate whether libertarians or compatibilists are right about the experience of the ability to do otherwise. Rather, I want to point out an important omission in this area. While nearly all the philosophical focus has been on the ability to do otherwise, there are other aspects of the phenomenology of freedom that are hardly ever discussed. To illustrate this, let me introduce another case.

Suppose a man has been diagnosed with cancer of the lungs. He is offered the options of chemotherapy or radiation treatment. At the level of cellular biology, the mechanisms of action of the respective treatments are quite different. Nonetheless, they are both similarly potentially life saving, and they both generate a similar profile of horrible side effects. One therapy is administered at St. Joseph's Hospital uptown while the other is administered at University Hospital downtown, but both hospitals are just as good and are at an exactly equal distance from the man's house. Thus the man has two options, but they aren't terribly divergent-in all the ways that matter to him, the two therapies are much the same.

Compare this man's subjective experiences as he chooses between the two options with what is experienced by the young man in Sartre's story. Recall that this young man chooses between fighting for the Resistance versus staying home with his mother-two ways of expressing himself that are utterly divergent in that they speak for completely different aspects of his self. I believe that the experiences of freedom of the two men in making their choice are quite different. The man who has cancer experiences the "narrowness" of his options. His options aren't at all divergent; they are both contained within a small region of option space. In contrast, the young man in Sartre's story feels the amazing distance between his two options. The gap that separates them is massive; it is dizzying to traverse it. As the young

\footnotetext{
33 See Nahmias et al. (2004) for a detailed discussion.
} 
man moves back and forth between his options, it feels like a trek between distant worlds. When the man diagnosed with cancer moves back and forth between his two options, he hardly shifts at all.

These examples illustrate that experiences of spaciousness and movement are important aspects of the phenomenology of freedom. It should be clear that these experiences are closely connected with latitude. Latitude is linked to the size of an option set; it consists of the potentialities for self-expression that are gained as one's option set grows. Correspondingly, the difference in the respective subjective experiences of these two men just discussed arises from the difference in option set size. That is, the option set of the young man is larger because the options within it are highly divergent, and the young man's freedom is experienced as movement back and forth within this expansive space.

Now consider the young woman thinking about what to do for Spring Break. Like Sartre's young man, she too has an option set of large size. In particular, she has numerous and varied options that give her diverse opportunities for selfexpression. But there is an additional aspect to her case: Even as she is deciding what to do, she is actively building new options. That is, she is deploying her potent powers of option construction to dream up new avenues for self-expression. If her space of options is sparsely covered in certain important regions, she will deploy her creative powers to fill it up. I believe this gives rise to an additional experience of freedom. In addition to spaciousness and movement, she experiences a feeling of unboundedness. Her option set is already expansive; it permits great movement within it. But in addition to this, its perimeter is not fixed; she has the power to enlarge it.

Nearly all philosophers who have discussed the phenomenology of freedom have done so in terms of the experience of the ability to do otherwise. If the feeling of freedom exclusively consists of the feeling that one has this ability, then there should be no difference at all amongst these three agents - the man diagnosed with cancer, Sartre's young man, and the young woman in college planning her Spring Break-in their respective subjective experiences of freedom. All three agents fully and equally have the ability to do otherwise. In particular, all three satisfy the conditions that compatibilist philosophers typically put forward as an analysis of this ability: Their actions depend on their relevant psychological states, i.e., their motives, evaluations, and assessments of reasons, such that were these states to differ, their actions would differ too.

I have argued, however, that the experiences of freedom of these three agents $d o$ differ. Sartre's young man and the young woman in college not only have more freedom, they subjectively experience more freedom than the man diagnosed with cancer. Moreover, this additional freedom they have is experienced in a characteristic way-not as the feeling that they could do otherwise, but rather as feelings of spaciousness and movement, and specifically in the case of the young women, feelings of unboundedness. The fact that the latitude account of free will readily makes sense of these other aspects of the phenomenology of freedom, while standard compatibilist views don't, is an important piece of evidence in favor of the latitude account. 


\section{Conclusion}

I want to conclude and summarize with the help of a final example.

A woman is considering what to do about a certain problem. She exercises her powerful abilities for option construction and builds a wide variety of options. These options consist of complex plans that unfold over extended stretches of time. Moreover, these options speak to her various conflicting cares; they afford her a diversity of opportunities for self-expression. As she deliberates, she experiences the spaciousness of her option set, and the feeling of movement as she wanders and explores within it. She selects the option that on balance best advances her interests. Were her evaluations of the options to be different, she would have done something else.

What makes this woman free? An influential set of compatibilist views says that she is free because she satisfies a control/could have done otherwise condition; roughly, her actions depend on her evaluations such that were her evaluations to be different, her actions would be different as well. In this essay, I have argued that this reply is incomplete. A control/could have done otherwise condition is satisfied by a wide variety of creatures in the animal world, only some of which enjoy the kind of freedom that humans have. This woman's freedom, I claimed, in addition depends on something else: latitude. The woman has exercised her powerful abilities for option construction to build an option set that contains numerous and diverse opportunities for self-expression. A critical part of the explanation of why she is free is that she can roam far and wide within this space of options-a space that is sufficiently latitudinous.

Acknowledgments This paper benefited from extensive comments from numerous individuals including Roy Baumeister, Sarah Buss, Victor Kumar, Neil Levy, Al Mele, Eddy Nahmias, Peter Railton, and Martin Seligman. Work on the paper was supported by a grant from the John Templeton Foundation, "Prospective Psychology Stage 1: Imagination and Being Drawn into the Future."

Open Access This article is distributed under the terms of the Creative Commons Attribution 4.0 International License (http://creativecommons.org/licenses/by/4.0/), which permits unrestricted use, distribution, and reproduction in any medium, provided you give appropriate credit to the original author(s) and the source, provide a link to the Creative Commons license, and indicate if changes were made.

\section{References}

Addis, D. R., Pan, L., Vu, M. A., Laiser, N., \& Schacter, D. L. (2008). Constructive episodic simulation of the future and the past: Distinct subsystems of a core brain network mediate imagining and remembering. Neuropsychologia, 47, 2222-2238.

Amabile, T. M., \& Gryskiewicz, N. D. (1989). The creative environment scales: Work environment inventory. Creativity Research Journal, 2, 231-253.

Baer, J. (1993). Creativity and divergent thinking: A task-specific approach (Vol. 8). Hillsdale, NJ: Lawrence Erlbaum Associates.

Bischof, N. (1980). On the phylogeny of human morality. In G. Stent (Ed.), Morality as a biological phenomenon (pp. 53-74). Berkeley, CA: University of California Press. 
Boyd, R., \& Richerson, P. J. (1988). Culture and the evolutionary process. Chicago, IL: University of Chicago Press.

Campbell, D. T. (1960). Blind variation and selective retentions in creative thought as in other knowledge processes. Psychological Review, 67, 380-400.

Clarke, R. (2006). Libertarian accounts of free will. New York, NY: Oxford University Press.

Clarke, R. (2009). Dispositions, abilities to act, and free will: The new dispositionalism. Mind, 118, 323-351.

Clayton, N. S., Dally, J., Gilbert, J., \& Dickinson, A. (2005). Food caching by western scrub-jays (Aphelocoma californica) is sensitive to the conditions at recovery. Journal of Experimental Psychology: Animal Behavior Processes, 31, 115-124.

Craig, J., \& Baron-Cohen, S. (1999). Creativity and imagination in autism and Asperger syndrome. Journal of Autism and Developmental Disorders, 29, 319-326.

De Brigard, F., \& Gessell, B. S. (2016). Time is not of the essence: Understanding the neural correlates of mental time travel. In S. B. Klein, K. Michaelian, \& K. K. Szpunar (Eds.), Seeing the future: Theoretical perspectives on future-oriented mental time travel. New York, NY: Oxford University Press.

Dehaene, S., Meyniel, F., Wacongne, C., Wang, L., \& Pallier, C. (2015). The neural representation of sequences: From transition probabilities to algebraic patterns and linguistic trees. Neuron, 88, 2-19.

Dennett, D. C. (1984). Elbow room: The varieties of free will worth wanting. Cambridge, MA: MIT Press.

Dennett, D. C. (2004). Freedom evolves (Reprint ed.). New York, NY: Penguin Books.

Fischer, J. M. (1987). Responsiveness and moral responsibility. In F. Schoeman (Ed.), Responsibility, character, and the emotions: New essays in moral psychology (pp. 81-106). Cambridge, MA: Cambridge University Press.

Fischer, J. M. (2012a). Responsibility and autonomy: The problem of mission creep. Philosophical Issues, 22, 165-184.

Fischer, J. M. (2012b). Semicompatibilism and Its rivals. The Journal of Ethics, 16, 117-143.

Fischer, J. M., \& Ravizza, M. (1998). Responsibility and control: A theory of moral responsibility. New York, NY: Cambridge University Press.

Fitch, W. T., \& Martins, M. D. (2014). Hierarchical processing in music, language, and action: Lashley revisited. Annals of the New York Academy of Sciences, 1316, 87-104.

Frankfurt, H. (1971). Freedom of the will and the concept of a person. The Journal of Philosophy, 68, $5-20$.

Franklin, C. E. (2014). Everyone thinks that an ability to do otherwise is necessary for free will and moral responsibility. Philosophical Studies, 172, 2091-2107.

Gentner, D., Brem, S., Ferguson, R., \& Wolff, P. (1997). Analogy and creativity in the works of Johannes Kepler. In T. B. Ward, S. M. Smith, \& J. Vaid (Eds.), Creative thought: An investigation of conceptual structures and processes (pp. 403-459). Washington, DC: American Psychological Association.

Gentner, D., Holyoak, K. J., \& Kokinov, B. N. (2001). The analogical mind: Perspectives from cognitive science. Cambridge, MA: MIT Press.

Gentner, D., \& Markman, A. B. (1997). Structure mapping in analogy and similarity. American Psychologist, 52, 45-56.

Gerrans, P., \& Kennett, J. (2010). Neurosentimentalism and moral agency. Mind, 119, 585-614.

Ginet, C. (2006). Working with Fischer and Ravizza's account of moral responsibility. The Journal of Ethics, 10, 229-253.

Holyoak, K. J., \& Thagard, P. (1996). Mental leaps: Analogy in creative thought. Cambridge, MA: MIT Press.

Huebner, B. (forthcoming). Planning and prefigurative politics: The nature of freedom and the possibility of control. In B. Huebner (Ed.), Essays on Dennett. New York: Oxford University Press.

Johnson-Laird, P. (1989). Analogy and the exercise of creativity. In S. Vosniadou \& A. Ortony (Eds.), Similarity and analogical reasoning. Cambridge, MA: Cambridge University Press.

Kennett, J., \& Matthews, S. (2009). Mental timetravel, agency and responsibility. In M. B. L. Bortolotti (Ed.), Psychiatry as cognitive neuroscience: Philosophical perspectives. Oxford: Oxford University Press.

Kim, K. H. (2008). Meta-analyses of the relationship of creative achievement to both IQ and divergent thinking test scores. The Journal of Creative Behavior, 42, 106-130.

Lashley, K. S. (1951). The problem of serial order in behavior. In L. A. Jeffress (Ed.), Cerebral mechanisms in behavior: The Hixon symposium (pp. 112-146). London: Wiley. 
Lind, S. E., \& Bowler, D. M. (2010). Episodic memory and episodic future thinking in adults with autism. Journal of Abnormal Psychology, 119, 896-905.

McKenna, M. (2011). Conversation and responsibility. New York, NY: Oxford University Press.

Miller, G. A., Galanter, E., \& Pribram, K. H. (1960). Plans and the structure of behavior (Vol. 29). New York, NY: Adams Bannister Cox.

Mulcahy, N. J., \& Call, J. (2006). Apes save tools for future use. Science, 312, 1038-1040.

Mumford, M. D., Blair, C., Dailey, L., Leritz, L. E., \& Osburn, H. K. (2006). Errors in creative thought? Cognitive biases in a complex processing activity. The Journal of Creative Behavior, 40, 75-109.

Nahmias, E. (forthcoming). Free will as a psychological accomplishment. In D. Schmidtz \& C. Pavel (Eds.), Oxford handbook on freedom. Oxford University Press.

Nahmias, E., Morris, S., \& Nadelhoffer, T. (2004). The phenomenology of free will. Journal of Consciousness Studies, 11, 162-179.

O'Conner, T. (2013). Free will. In E. N. Zalta (Ed.), The Stanford encyclopedia of philosophy (Spring 2013 Edition). Retrieved from http://plato.stanford.edu/archives/spr2013/entries/freewill/.

Osvath, M., \& Osvath, H. (2008). Chimpanzee (Pan troglodytes) and orangutan (Pongo abelii) forethought: Self-control and pre-experience in the face of future tool use. Animal Cognition, 11, 661-674.

Pereboom, D. (2001). Living without free will. Cambridge; New York: Cambridge University Press.

Pyke, G. H. (1984). Optimal foraging theory: A critical review. Annual Review of Ecology and Systematics, 15, 523-575.

Pyke, G. H., Pulliam, H. R., \& Charnov, E. L. (1977). Optimal foraging: A selective review of theory and tests. The Quarterly Review of Biology, 52, 137-154.

Raby, C. R., Alexis, D. M., Dickinson, A., \& Clayton, N. S. (2007). Planning for the future by western scrub-jays. Nature, 445, 919-921.

Railton, P. (2014). The affective dog and its rational tale: Intuition and attunement. Ethics, 124, 813-859.

Roberts, W. A. (2002). Are animals stuck in time? Psychological Bulletin, 128, 473-489.

Rosenbaum, D. A., Cohen, R. G., Jax, S. A., Weiss, D. J., \& van der Wel, R. (2007). The problem of serial order in behavior: Lashley's legacy. Human Movement Science, 26, 525-554.

Runco, M. A. (1991). Divergent thinking (Vol. 11). Westport, CT: Ablex Publishing.

Schacter, D. L., \& Addis, D. R. (2007). The cognitive neuroscience of constructive memory: Remembering the past and imagining the future. Philosophical Transactions of the Royal Society B: Biological Sciences, 362, 773-786.

Schultz, W. (2010). Dopamine signals for reward value and risk: Basic and recent data. Behavioral and Brain Functions, 6, 1-9.

Schultz, W., Dayan, P., \& Montague, P. R. (1997). A neural substrate of prediction and reward. Science, 275, 1593-1599.

Searle, J. R. (1984). Minds, brains and science. Cambridge, MA: Harvard University Press.

Seligman, M. E. P., Railton, P., Baumeister, R. F., \& Sripada, C. (2013). Navigating into the future or driven by the past. Perspectives on Psychological Science, 8, 119-141.

Simonton, D. K. (1999). Creativity as blind variation and selective retention: Is the creative process Darwinian? Psychological Inquiry, 10, 309-328.

Sripada, C. (2015). Self-expression: A deep self theory of moral responsibility. Philosophical Studies, 1-30. doi:10.1007/s11098-015-0527-9.

Sternberg, R. J., \& Lubart, T. I. (1991). An investment theory of creativity and its development. Human Development, 34, 1-31.

Suddendorf, T., \& Busby, J. (2003). Mental time travel in animals? Trends in Cognitive Sciences, 7, 391-396.

Suddendorf, T., \& Corballis, M. C. (2007). The evolution of foresight: What is mental time travel, and is it unique to humans? Behavioral Brain Science, 30, 299-313. (discussion 313-51).

Szpunar, K. K., Spreng, R. N., \& Schacter, D. L. (2014). A taxonomy of prospection: Introducing an organizational framework for future-oriented cognition. Proceedings of the National Academy of Sciences, 111, 18414-18421.

Tomasello, M. (1999). The human adaptation for culture. Annual Review of Anthropology, 28, 509-529.

Tomasello, M. (2009). The cultural origins of human cognition. Cambridge, MA: Harvard University Press.

Watson, G. (1975). Free agency. The Journal of Philosophy, 72, 205-220.

Watson, G. (2001). Reason and responsibility. Ethics, 111, 374-394.

Wolf, S. (1993). Freedom within reason. New York, NY: Oxford University Press. 